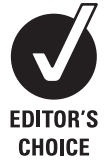

School of Physiotherapy, La Trobe University, Bundoora, Victoria, Australia

Correspondence to: Mr Ross lles, School of Physiotherapy, La Trobe University, Bundoora, Victoria 3086, Australia; r.iles@latrobe.edu.au

Accepted 22 February 2008 Published Online First 16 April 2008

\title{
Psychosocial predictors of failure to return to work in non-chronic non-specific low back pain: a systematic review
}

\author{
R A lles, M Davidson, N F Taylor
}

\begin{abstract}
Objectives: To identify psychosocial predictors of failure to return to work in non-chronic (lasting less than 3 months) non-specific low back pain (NSLBP).
\end{abstract}

Methods: A systematic review of prognostic studies was carried out. Medline, Embase, PsychINFO, CINAHL and PEDro electronic bibliographic databases up to April 2006 were searched. Included studies took baseline measures in the non-chronic phase of NSLBP (ie, within 3 months of onset), included at least one psychosocial variable and studied a sample in which at least $75 \%$ of participants had NSLBP. Baseline measures had to be used to predict at least one work-specific outcome.

Results: The search identified 24 studies meeting the inclusion criteria. From these studies there is strong evidence that recovery expectation is predictive of work outcome and that depression, job satisfaction and stress/ psychological strain are not predictive of work outcome. There is moderate evidence that fear avoidance beliefs are predictive of work outcome and that anxiety is not predictive of work outcome. There is insufficient evidence to determine whether compensation or locus of control are predictive of work outcome.

Conclusions: To predict work outcome in non-chronic NSLBP, psychosocial assessment should focus on recovery expectation and fear avoidance. More research is needed to determine the best method of measuring these constructs and to determine how to intervene when a worker has low recovery expectations.

Non-specific low back pain (NSLBP) is common, with up to $90 \%$ of adults experiencing low back pain at some stage in their lives. ${ }^{1-3}$ Typically episodes of NSLBP are resolved within weeks, ${ }^{145}$ but when NSLBP prevents a person from working there are personal, social and economic consequences. Work absence due to NSLBP costs millions of dollars worldwide due to decreased productivity, treatment costs and ongoing compensation payments. ${ }^{145} \mathrm{~A}$ small proportion of people experiencing ongoing disability due to NSLBP consume the majority of resources devoted to $\mathrm{NSLBP}^{4}{ }^{6}$ and, as a result, emphasis on early identification of these individuals has increased. One premise behind the idea of early, accurate prognosis is that intervention at an appropriate phase of NSLBP will prevent the development of chronic work disability.

Previous reviews have included studies examining chronic NSLBP, ${ }^{7}$ have examined outcomes other than work-specific outcomes, ${ }^{4-11}$ have included a mixture of participants with NSLBP and other musculoskeletal conditions ${ }^{3412}$ or have focused on methodological issues in the existing prognosis literature. ${ }^{13} 14$ The review by Steenstra et a ${ }^{15}$ included only studies of acute NSLBP and focused on work outcomes but included retrospective studies and did not focus on psychosocial predictors of failure to return to work. Therefore, the aim of the current review was to identify psychosocial predictors of failure to return to work in non-chronic (lasting less than 3 months) NSLBP.

\section{METHODS}

\section{Search strategy}

Guidelines of the Cochrane Back Review Group ${ }^{16}$ were used to develop a search strategy that would identify studies relevant to the research question. The search strategy had four elements: low back pain, psychosocial predictor variables, return to work outcomes and a filter to identify prognostic publication types. Search terms were mapped to subject headings or MeSH terms wherever possible and to capture all relevant studies, synonymous terms were grouped together with the OR operator. Where no prognosis filter was available for a specific database, one was developed using the content of filters from other databases. ${ }^{17}$ The search strategy was applied in the Medline, Embase, PsychINFO, CINAHL and PEDro electronic bibliographic databases up to April 2006. The search strategy used in the Medline database is given in the appendix. Reference lists of relevant studies and systematic reviews were examined to identify additional publications.

\section{Inclusion criteria}

The review was limited to studies published in English in peer-reviewed journals. Retrospective studies were not included due to the potential bias in this type of study. ${ }^{18}$ Two reviewers (RI and NT) independently applied the exclusion criteria and the following inclusion criteria to the titles and abstracts:

- baseline measures applied for $>75 \%$ of inception cohort within 3 months of onset or recurrence of NSLBP (ie, sample was in the non-chronic phase of NSLBP),

- baseline measures included at least one psychosocial variable,

- baseline measures were used to predict at least one work-specific outcome.

Where it was not clear from the title and abstract whether the study met inclusion criteria, the full text of the article was examined. Consensus was used to resolve any disagreements between reviewers and if consensus was not achieved, a third reviewer was consulted (MD). 


\section{Quality assessment}

In the current review the quality of the included studies was rated on 17 criteria (table 1) which were derived from two systematic reviews on the prognosis of NSLBP ${ }^{13}{ }^{14}$ and addressed six major sources of bias in prognostic reviews. ${ }^{19}$

In particular the quality criteria addressed bias in the form of study participation (S1-S6), prognostic factor measurement (PI1-PI4) and outcome measurement (FU1 and FU4). Each criterion was answered "yes", "no" or "can't tell". Two independent reviewers ( $\mathrm{RI}$ and $\mathrm{MD}$ ) assessed the quality of each included study and disagreements were resolved by discussion. Full details of the quality assessment criteria are available from the corresponding author on request. No studies were excluded on the basis of quality, but the results of quality assessment were taken into account when drawing conclusions using a method similar to those used in previous reviews. ${ }^{8} 1520$ Studies with a total score of 12 or more criteria answered yes were considered high quality, those with 10 or 11 criteria moderate quality, and with nine or less low quality.

\section{Levels of evidence}

The evidence that commonly measured constructs did or did not predict work outcome was considered to be strong, moderate or insufficient in a manner similar to previous reviews. ${ }^{8} 1520$ In order for the level of evidence to be strong, findings had to be consistent in multiple high quality studies. Moderate evidence required either consistent findings in one high quality study and one or more moderate quality studies or consistent findings across multiple moderate and lower quality studies. When there were findings from only one study or inconsistent findings across multiple studies, the evidence was considered to be insufficient.

\section{Table 1 Quality criteria}

\begin{tabular}{|c|c|}
\hline \multicolumn{2}{|l|}{ Sample } \\
\hline S1 & Study provided clearly defined inclusion and exclusion criteria \\
\hline S2 & The stage when initial measures were applied was clearly stated \\
\hline S3 & $\begin{array}{l}\text { Measures were applied at an appropriate stage to investigate the } \\
\text { research question }\end{array}$ \\
\hline S4 & The study used representative sampling techniques \\
\hline S5 & Important characteristics of the sample were described \\
\hline S6 & The setting and study site were clearly described \\
\hline \multicolumn{2}{|c|}{ Prognostic indicators } \\
\hline PI1 & Clearly defined constructs of what is measured were provided \\
\hline $\mathrm{PI} 2$ & Justification of the measures used was given \\
\hline $\mathrm{PI} 3$ & $\begin{array}{l}\text { The selection of prognostic indicators recognises the multifactorial nature } \\
\text { of RTW }\end{array}$ \\
\hline $\mathrm{PI} 4$ & $\begin{array}{l}\text { The study used standardised, psychometrically sound instruments for all } \\
\text { measures taken }\end{array}$ \\
\hline \multicolumn{2}{|c|}{ Analysis } \\
\hline $\mathrm{A} 1$ & $\begin{array}{l}\text { Multivariate techniques were used to adjust for potential confounding } \\
\text { variables }\end{array}$ \\
\hline A2 & The analysis avoided over-fitting the data \\
\hline A3 & Prospective validation in another cohort was performed \\
\hline \multicolumn{2}{|c|}{ Follow-up } \\
\hline FU1 & $\begin{array}{l}\text { RTW outcome was defined in detail, or measure was of sick leave } \\
\text { duration }\end{array}$ \\
\hline FU2 & The duration of follow-up was greater than or equal to 6 months \\
\hline FU3 & $\begin{array}{l}\text { The data were complete for at least } 80 \% \text { of the sample measured at } \\
\text { baseline }\end{array}$ \\
\hline FU4 & Outcome measurements were blinded \\
\hline
\end{tabular}

Requirements to satisfy quality criteria are available from the corresponding author on request. RTW, return to work.

\section{Data extraction}

Psychosocial variables and how they were measured were extracted from each study. Results were listed under three headings: univariate results, multivariate results and predictive models. Univariate results list the variables that were found to be significantly different between groups experiencing a positive or negative outcome when tested by a simple univariate test (such as a t test or $\chi^{2}$ analysis). Multivariate results were variables found to be significantly different between groups experiencing a particular outcome when tested by more complex multivariate analysis, such as multiple regression or hazard ratios. When the accuracy, sensitivity or specificity of a model was presented in a study, the predictive model was considered to have been tested. In this case the factors making up the model were listed as part of a predictive model.

\section{RESULTS}

The search strategy resulted in an initial yield of 997 references. The full texts of 50 studies were retrieved and examined and 31 did not meet inclusion criteria (17 did not apply baseline measures in the non-chronic phase of NSLBP, four did not examine prognosis, three examined a cohort consisting of less than $75 \%$ NSLBP, two were retrospective studies, two did not include a work-specific outcome, two did not measure any psychosocial variables and one was a comment on a previous study and not applicable to this review).

Examination of reference lists of relevant systematic reviews and studies meeting inclusion criteria identified five studies not identified by the electronic search ${ }^{21-25}$ that met inclusion criteria. Two separate publications ${ }^{26}{ }^{27}$ were derived from the same sample and were therefore considered a single study. The final number of studies included in the review was 24. A summary of the included studies is presented in table 2 .

The quality assessment revealed major shortcomings in the over-fitting of multivariate models and the failure to validate models in a new sample. Blinded outcome assessors and representative sampling techniques were infrequently used, descriptions of the study setting were often absent and the majority of studies failed to define their major outcome. These limitations are similar those described in previous reviews of prognostic studies. ${ }^{7}{ }^{1314}$ The majority of studies (13) were of low quality, with seven moderate quality studies and four high quality studies (table 3). Full details of quality analysis can be obtained on request from the author.

Table 3 lists the seven most frequently measured psychosocial constructs, how the construct was measured and the outcome that was predicted. Also shown is whether each variable was found to be a significant predictor in univariate or multivariate analysis and whether the construct formed part of a model tested for its predictive accuracy. The level of evidence for each construct as a predictor of work outcome in non-chronic NSLBP is summarised in table 4.

\section{DISCUSSION}

\section{Recovery expectation}

There is strong evidence that recovery expectation regarding return to work is predictive of work outcome (table 4). This finding is supported by all nine studies that measured it, including all four high quality studies ${ }^{30} 323644$ and one moderate quality study. ${ }^{23}$ A review by Mondloch et a ${ }^{48}$ identified that 15 out of 16 moderate or better methodological quality studies measuring recovery expectation found positive expectations were associated with better health outcomes across a range of clinical 
Table 2 Characteristics of the included studies

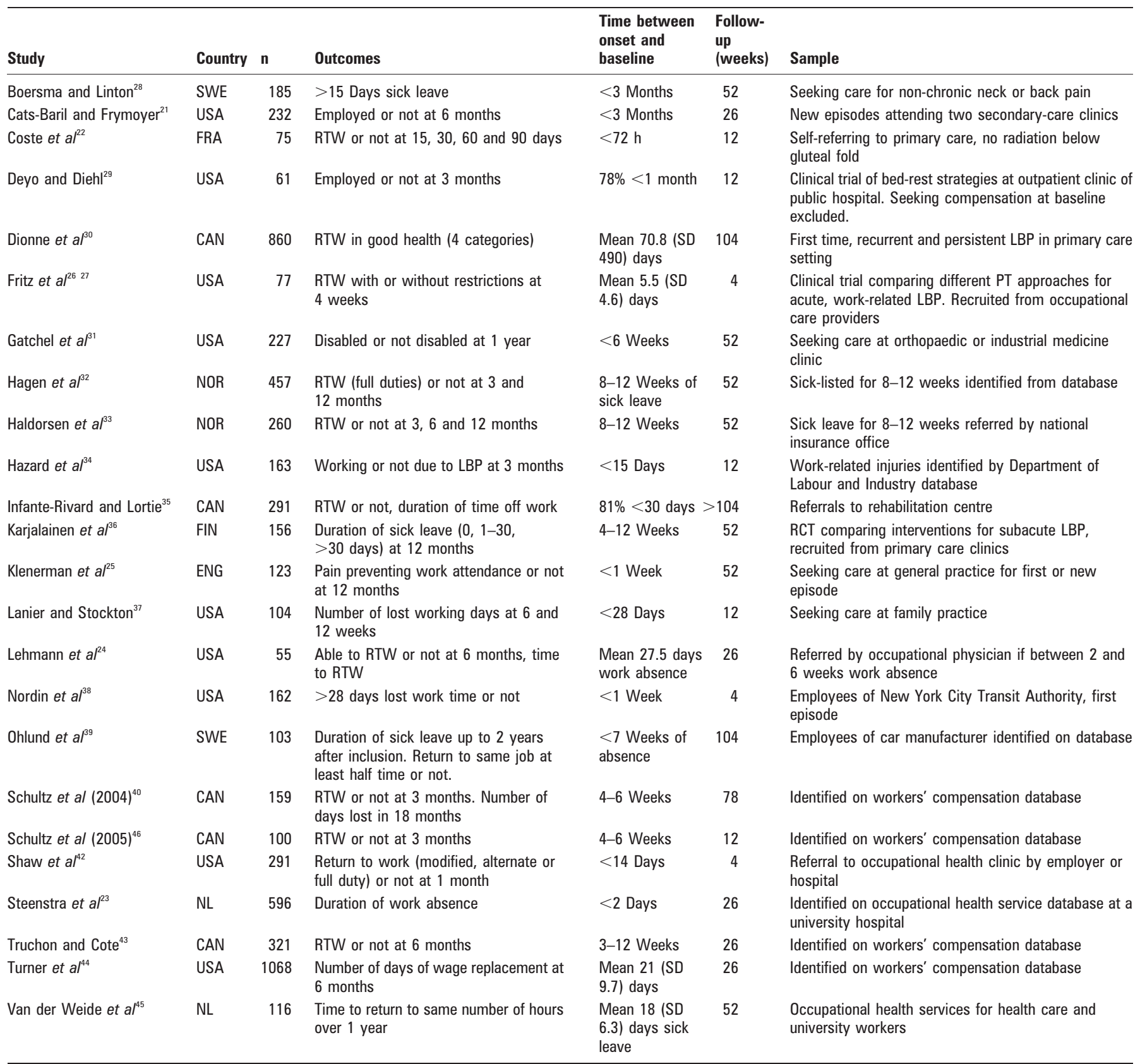

LBP, low back pain; PT, physiotherapy; RCT, randomised controlled trial; RTW, return to work.

conditions, including work outcomes in low back pain and myocardial infarction. Others have found positive recovery expectations associated with positive health outcomes in chronic NSLBP, ${ }^{79}$ total knee replacement surgery, ${ }^{50}$ cardiac surgery ${ }^{51}$ and return to work after acute soft tissue injury. ${ }^{53}$ It is likely recovery expectation combines variables across multiple constructs that would be too numerous or too difficult to measure individually via questionnaire, physical examination or interview. This information is likely filtered through the experiences, beliefs and attitudes of the individual, resulting in a realistic prediction of when return to work will occur. Qualitative investigation of workers with occupational NSLBP has revealed that outcome expectancies span four major domains of outcome (job/financial security, re-injury, workplace support and self-image). ${ }^{47}$ Recovery expectation is a complex construct that appears to be a robust predictor of return to work.
Less clear is how strong a predictor recovery expectation is. Across the studies, little information was provided regarding the prevalence or predictive accuracy of poor recovery expectations. Turner et $a l^{44}$ provided detailed information regarding recovery expectations and subsequent outcomes of participants. Of 1018 participants who answered the item, 96 (9\%) rated their certainty of working in 6 months as less than 5 out of 10 . This increased the chances of developing long term disability by around $30 \%$. However, recovery expectation had limited value in determining who would return to work within 6 months. This suggests that while recovery expectation is a significant predictor of work disability, it may not hold enough predictive strength to be used as a predictor on its own.

The best method of measuring work-related recovery expectation remains unclear. The majority of studies used single items to measure recovery expectation, except for Schultz et al, ${ }^{40} 46$ but 
Table 3 Common psychosocial constructs measured and significance in predicting outcome

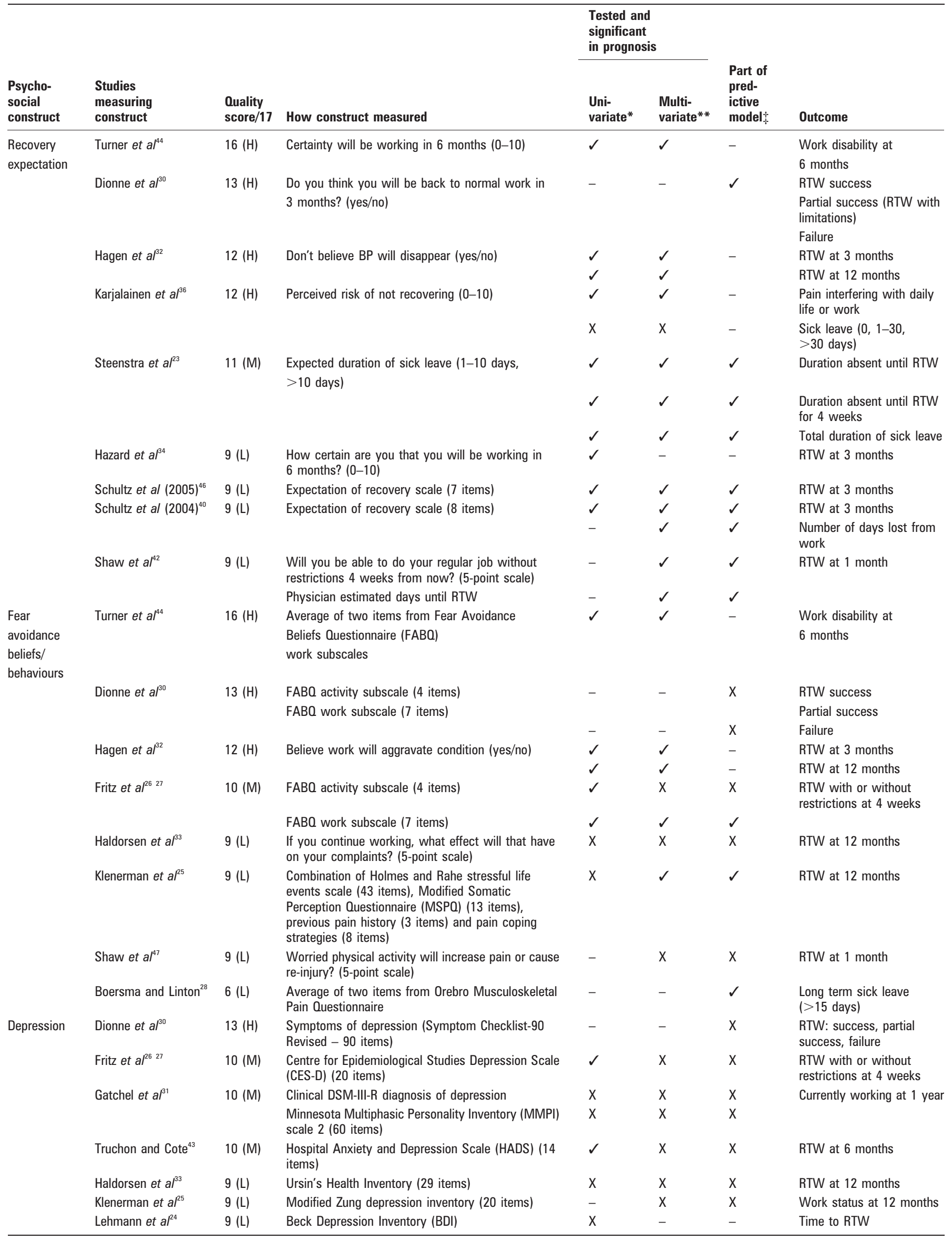


Table 3 Continued

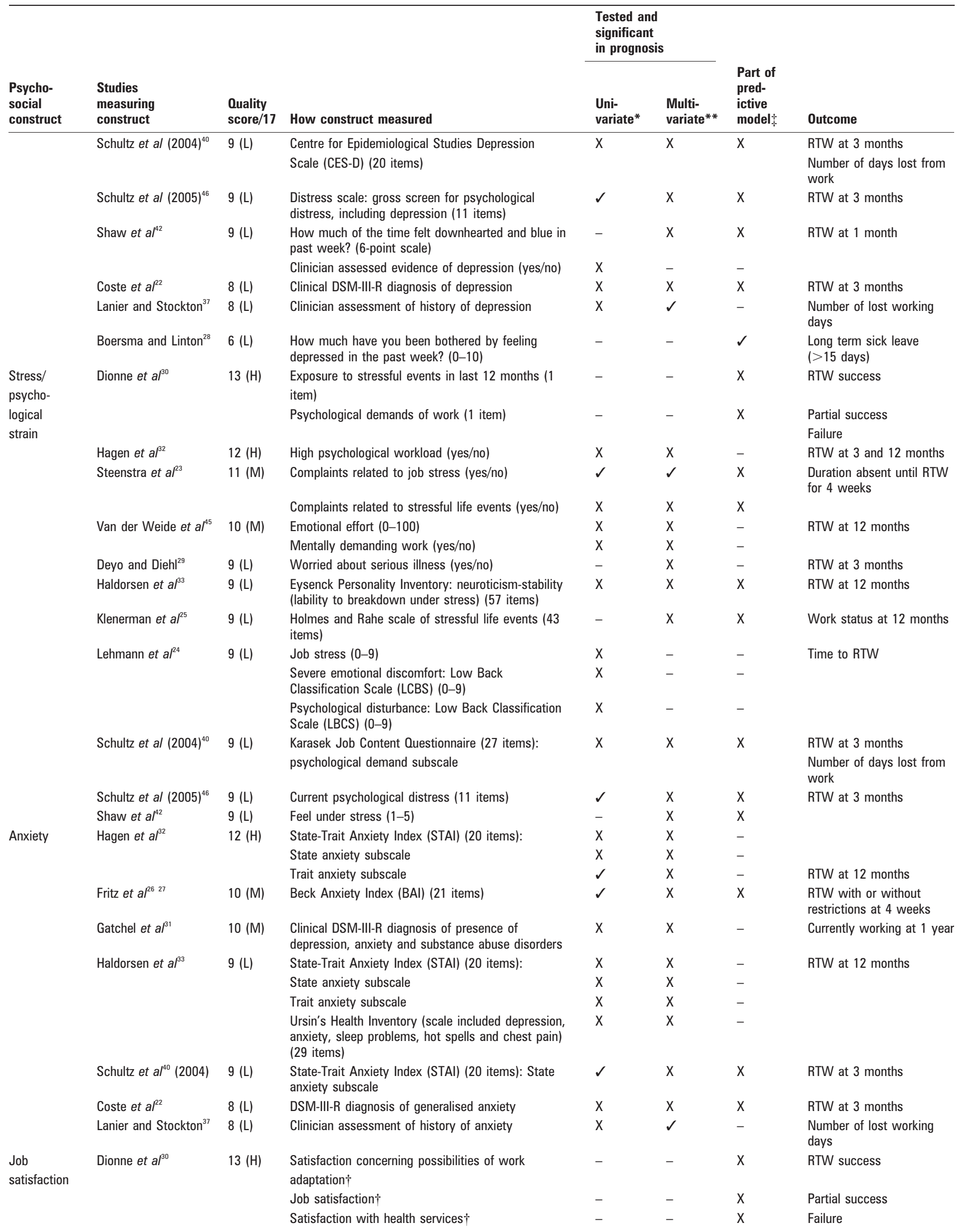


Table 3 Continued

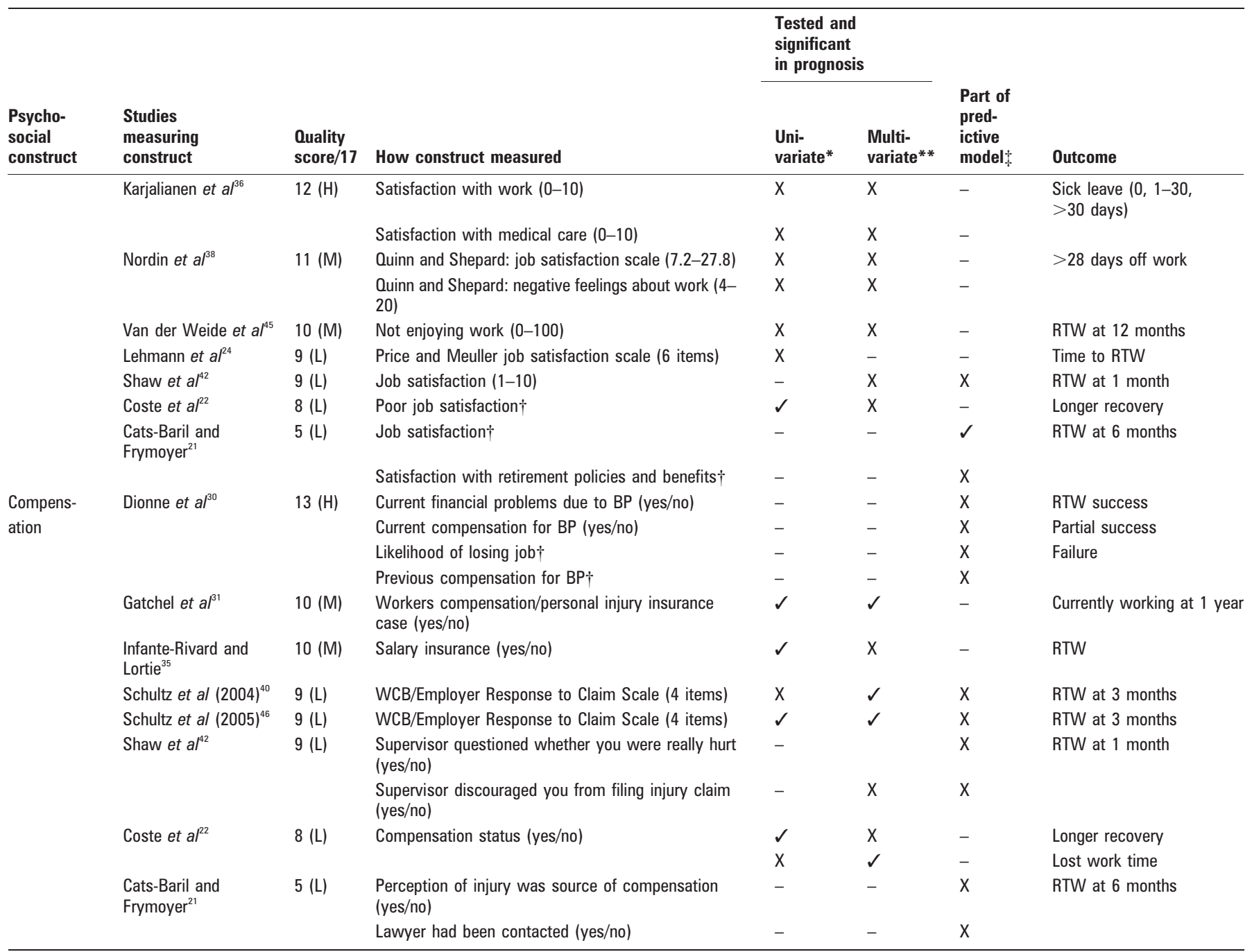

${ }^{*}$ Significant $(\mathrm{p}<0.05)$ in univariate test comparing groups, such as $t$ test or $\chi^{2}$ analysis.

${ }^{* *}$ Significant $(p<0.05)$ in multivariate test comparing groups, such as multiple regression or Cox hazard ratios.

$\uparrow$ No further information presented in study.

$\$$ Prognostic model tested to determine sensitivity, specificity or accuracy of predicting outcomes.

$\checkmark$, tested and found significant, or used as part of tested predictive model; -, not assessed in this category (univariate testing not carried out, multivariate testing not carried out, predictive model not tested); $\mathrm{X}$, tested and not found significant in predicting outcome, or not included in tested prognostic model.

Studies are listed in each section with highest methodological quality first. $\mathrm{H}$, high quality study with quality score of 12 or greater out of 17 ; $\mathrm{L}$, low quality study with quality score of 9 or less out of $17 ; \mathrm{M}$, medium quality study with quality score of 10 or 11 out of 17 .

BP, back pain; DSM-III-R, Diagnostic and Statistical Manual of Mental Disorders, Third Edition, Revised; FABQ, Fear Avoidance Beliefs Questionnaire; RTW, return to work; WCB, Workers' Compensation Board.

detailed contents of the multiple item scales were not provided. A three-item scale measuring work-related recovery expectation has been examined and applied in a chronic NSLBP setting, ${ }^{49}{ }^{54}$ but further research is needed to determine the validity and reliability of single measures and scales measuring recovery expectations in non-chronic NSLBP.

While the best method of measuring recovery expectation requires further investigation, recovery expectation can provide an indication of whether psychosocial factors need to be addressed in the treatment of NSLBP. When a person indicates low expectations for recovery, it is likely they have synthesised a myriad of variables (personal, psychosocial and environmental) and have identified factors that may hinder their recovery and return to work. Low recovery expectations do not indicate which intervention is appropriate, but do invite a practitioner to investigate further the reasons why the person believes their recovery may be delayed.

\section{Fear avoidance beliefs/behaviours}

There is moderate evidence that fear avoidance beliefs are predictive of work outcome (table 4). Five out of eight studies found fear avoidance beliefs and behaviours to be a significant predictor of work-related outcome, two of which were of high methodological quality. ${ }^{32} 44$ However, one high quality study ${ }^{30}$ did not find fear avoidance beliefs significant when developing a clinical algorithm to predict work outcome.

Pain is a strong aversive stimulus, and fear of pain can result in avoidance of situations where pain may be induced. ${ }^{55}$ Fear avoidance beliefs and behaviours are mediated by a worker's anticipation of how much pain a particular activity will produce, which tends to be greater than levels that are actually experienced. ${ }^{55-60}$ As a result, pain-related fear can lead to greater perceived disability, deconditioning and decreased functional performance..$^{57-61}$ The presence of fear avoidance beliefs and behaviours has been identified as a possible method of 
Table 4 Levels of evidence for constructs as prognostic indicators for work outcome

\begin{tabular}{ll}
\hline Construct & Evidence level \\
\hline Recovery expectation & ++ \\
Fear avoidance & + \\
Job satisfaction & -- \\
Depression & -- \\
Stress/psychological strain & -- \\
Anxiety & - \\
Compensation & 0 \\
Locus of control & 0 \\
\hline
\end{tabular}

++ , Strong evidence is predictor of work outcome; + , moderate evidence is a predictor of work outcome; 0 , insufficient evidence is a predictor of work outcome; -, moderate evidence is not a predictor of work outcome; --, strong evidence is not a predictor of work outcome.

identifying people at risk of ongoing problems in the acute stages of injury. ${ }^{59} 606263$

The role of fear avoidance behaviours in chronic pain and in the transition from acute to chronic pain has been established in the literature, ${ }^{12}{ }^{6465}$ however the predictive role of fear avoidance is not clear in the acute stage. The review by Pincus et $a^{166}$ of prospective cohorts with acute low back pain found little evidence to link fear of pain with poor outcome. However, only two of the nine studies included by those authors measured work-specific outcomes and this may explain the contrast in findings to the current review. During the acute phase of NSLBP fear avoidance behaviours are a natural response to sensory information delivered to the central nervous system, and the presence of avoidant beliefs and behaviours could be considered a normal, protective response. However, poor prognosis could be related to an exaggerated level of pain-related fear in the acute stage, or the persistence of avoidant behaviours beyond an acute timeframe. The results of the present review indicate that assessing fear avoidance beliefs and behaviours may be useful in determining work prognosis in people with non-chronic NSLBP.

Similar to recovery expectations, the best method of measuring fear avoidance beliefs is not clear. The Fear Avoidance Beliefs Questionnaire (FABQ $)^{55}$ was the most commonly used measurement tool, but this method combines a mixture of psychosocial constructs. For example, the work subscale includes constructs of fear avoidance, injury compensation and recovery expectation. Psychosocial constructs are often difficult to isolate using questionnaires as many constructs have some overlap, underlining the importance of using appropriate tools to limit potential bias when measuring prognostic factors. ${ }^{19}$

\section{Depression}

There is strong evidence that depression is not predictive of work outcome in non-chronic NSLBP (table 4). While an association between depression and chronic pain has been established, it remains unclear whether depression can be considered a cause of long term disability or a consequence of it. ${ }^{67}$ Depression can directly impact the outcome of rehabilitation programmes ${ }^{68}$ and has been identified as contributing to work-related disability. ${ }^{69-71}$ The review by Pincus et al ${ }^{11}$ found distress (encompassing depressive symptoms, depressive mood and psychological distress) was a significant predictor of progression from acute to chronic low back pain, however none of the studies included by Pincus et al studied return to work as the outcome. The reviews by Steenstra et $a l^{15}$ and Truchon and Fillion ${ }^{4}$ both focused on work outcomes and found depression was not a useful indicator of longer absence. It is possible depression is more likely to be a consequence of work disability rather than a cause and while depression may have a role in the development of chronic low back pain, depression does not predict ongoing work disability.

\section{Stress and anxiety}

There is strong and moderate evidence, respectively, that stress and anxiety are not predictive of work outcome in people with non-chronic NSLBP (table 4). Anxiety and stress have been closely linked to depression, ${ }^{57} 58$ 72-74 and the increase in time pressure and job intensification in today's workforce has been shown to have an impact on the mental health of workers. ${ }^{57} 7273$ High levels of stress and anxiety could further delay return to work as increased fatigue and high work demands may impact negatively on the worker's self-assessed ability to perform work tasks effectively,,$^{57}$ a major motivator when returning to work. ${ }^{75}$ Despite the potential for stress and anxiety to predispose a worker to longer work disability, stress and anxiety are not predictive of a poor work outcome in the non-chronic phase of NSLBP. The review by Linton et al ${ }^{13}$ found strong evidence to suggest stress increased the risk of future back pain, but reviews including a return to work outcome found little evidence for the predictive value of stress or anxiety, ${ }^{34815}$ supporting the findings of the current review.

\section{Job satisfaction}

There is strong evidence that job satisfaction is not predictive of work outcome in non-chronic NSLBP (table 4). It may be postulated that low job satisfaction may predispose a worker to longer work absence by impacting on motivation to return to work. Other workplace factors, such as structure, work content and relationships with work colleagues, have also been identified as impacting on return to work. Social support, interaction with colleagues and the perception that work tasks are important appear to be particularly relevant. ${ }^{75-79}$ These aspects may have a greater positive effect on motivation to return to work than any negative influence of overall low job satisfaction. As a result, the level of job satisfaction does not appear to delay the return to work process. ${ }^{80}$ The review by Truchon and Fillion, ${ }^{4}$ which included seven of the studies included in the current review, found mixed evidence that job satisfaction could predict functional outcome. The review by Linton, ${ }^{9}$ which included studies of acute and chronic NSLBP cohorts, found job satisfaction to be predictive of poorer outcome in all included studies except one examining return to work as the outcome, supporting the findings of the current review that job satisfaction is not predictive of work outcome in non-chronic NSLBP.

\section{Compensation}

There is insufficient evidence to conclude that compensation status is predictive of work outcome (table 4). Various compensation systems operate worldwide, and their effects on the return to work process are likely to be highly contextual. The current review includes studies from seven different countries and, given that systems of compensation can vary across regions within a country, more than seven systems are represented. The information provided in the included studies regarding the compensation systems in place was generally poor, making it difficult to compare studies on this variable. Regardless of the system in place, compensation can have therapeutic and anti-therapeutic impacts on return to work. ${ }^{81}$ While attempts have been made in different systems to remove 
adversarial aspects of the compensation process, the legal contesting of claims still exists in some form or another across different systems. ${ }^{81}{ }^{82}$ The consequences of compensation are complex and almost certainly have a psychosocial impact on a worker returning to work after injury, ${ }^{81}{ }^{83}$ but the extent to which compensation affects return to work is likely to be specific to the system in place. Previous reviews of the literature have failed to find compensation status to be predictive of outcome, ${ }^{34-111415}$ supporting the finding of the current review that there is insufficient evidence to determine whether compensation is predictive of work outcome in non-chronic NSLBP

The aim of prognosis in NSLBP is to identify individuals at risk of poor outcomes early in the course of NSLBP in order to provide appropriate intervention and improve the outcome. A range of psychosocial constructs have been investigated, but according to the evidence from the current review only recovery expectation and fear avoidance beliefs are consistently predictive of poor work outcome. These two constructs should be measured early in the course of NSLBP to identify a worker at risk, however the best method of measuring these constructs cannot be determined from this review. Whatever method is chosen, simply measuring recovery expectations can alert the treating practitioner that the individual may be at risk of ongoing work disability. Early assessment provides the treating practitioner with an indication of whether any adjustment to the treatment plan is necessary. Whether this involves referral to another professional or simply allowing greater time to discuss the impact of NSLBP for the individual, earlier intervention means the risk of poor work outcome can at least be addressed.

Chronic NSLBP requires a different treatment approach to acute NSLBP, which has led to biopsychosocial and behavioural approaches to the treatment of back pain. ${ }^{84} 85$ One of the reasons a different approach is needed is that psychosocial factors become associated with ongoing disability. Since psychosocial factors can have a large impact on return to work after a back injury, examining psychosocial factors appears to be an important part of prognosis. Psychosocial factors, however, are not the only constructs to consider when determining which individuals are at risk of poor work outcome. Factors such as initial pain intensity, ${ }^{34915}$ initial level of functional disability ${ }^{3}{ }^{15}$ and work factors ${ }^{3}{ }^{15}$ must also be considered. Examining recovery expectation and fear avoidance beliefs for prognosis of work outcome must be considered in light of these other factors

\section{Rationale for this review}

More than 10 previous reviews on prognosis and NSLBP currently exist. The current review captures information from participants across the whole non-chronic phase of NSLBP, incorporates quality assessment when making decisions regarding the importance of each construct and contains minimal overlap from previous reviews, with only seven of the 24 included studies represented in previous reviews. As a result, the current review is a summary of new information in the arena of NSLBP prognosis regarding the predictive ability of commonly measured psychosocial constructs. Several of the previous reviews assessed the quality of included studies but did not incorporate quality assessment when drawing conclusions regarding the level of evidence for predictors of outcome, ${ }^{349}$ and others excluded studies from review according to quality criteria. ${ }^{70}$ The current review incorporated quality assessment when determining the level of evidence for each predictor in a

\section{Main messages}

Recovery expectation and fear avoidance beliefs are predictive of work outcome in the non-chronic phase of NSLBP.

- Depression, job satisfaction, stress/psychological strain and anxiety are not predictive of work outcome in the non-chronic phase of NSLBP.

- Psychosocial assessment in the non-chronic phase of NSLBP to identify workers at risk of developing ongoing work disability should focus on recovery expectation and fear avoidance beliefs/behaviours.

\section{Policy implications}

- Measurement of psychosocial predictors of poor work outcome should focus on recovery expectations and fear avoidance beliefs in the non-chronic phase of non-specific low back pain (NSLBP). Other psychosocial constructs have little predictive value in the non-chronic phase.

- Recovery expectation can easily be included as part of routine early assessment of non-chronic NSLBP. Low expectations of recovery increase the risk of poor work outcome and flag the need for further assessment of psychosocial factors that may impact recovery.

manner similar to that of Steenstra et $a l^{15}$ and Hartvigsen et al, ${ }^{8}$ however Hartvigsen et al examined only psychosocial factors in the workplace. Steenstra et al examined any predictor of failure to return to work but only included studies with participants within 6 weeks of NSLBP onset.

\section{Limitations of the current review}

The strength of the current review is that the methodology closely follows the QUORUM guidelines for meta-analyses and systematic reviews. ${ }^{86}$ The findings of the current review are limited to psychosocial predictors of work outcome in nonchronic NSLBP and do not address physical or environmental factors that may impact work outcome. The current review required baseline measures to be applied within 12 weeks of injury onset and therefore assumes all workers over this period have a similar chance of return to work. However, length of time off work itself is a potential confounder as a worker who has missed 1 week of work due to their injury has a better prognosis than a worker who has missed 12 weeks of work. ${ }^{4} 512$ The current review also assumes prognostic indicators are stable over the non-chronic phase of NSLBP, meaning a psychosocial construct has the same prognostic value at 1 week after injury as it does 12 weeks after injury. Again, this may not be the case. ${ }^{12}$ However, the timing of the baseline measures of studies included in this review span the period described as non-chronic with no particular bias towards earlier or later prognostic indicators. Therefore the results of the review are likely to be generalisable across the non-chronic phase of NSLBP.

\section{CONCLUSION}

Strong evidence exists that recovery expectation is a predictor of work outcome and moderate evidence that fear avoidance beliefs are a predictor of work outcome in the non-chronic phase of NSLBP. Anxiety, depression, job satisfaction and 
stress/psychological strain are not predictive of work outcome in non-chronic NSLBP. There is insufficient evidence that the effect of compensation is predictive of work outcome.

Recovery expectation is a construct that takes into account a myriad of variables that would otherwise be too difficult or timeconsuming to measure, and filters them through the person's own beliefs and experiences. The importance of fear avoidance beliefs in chronic pain has been established and it appears these beliefs and behaviours also play an important role in the non-chronic phase of NSLBP and can assist in predicting work outcome. Recovery expectation and fear avoidance beliefs/behaviours are the psychosocial constructs of most value in guiding early intervention to prevent work disability due to NSLBP.

Funding: Rl is supported by an Australian Postgraduate Award.

Competing interests: None.

\section{REFERENCES}

1. Waddell G. The epidemiology of low back pain. In: The back pain revolution. 2nd ed. Edinburgh: Churchill Livingstone, 2004:27-44.

2. Walker BF, Muller R, Grant WD. Low back pain in Australian adults: prevalence and associated disability. J Manipulative Physiol Ther 2004;27:238-44.

3. Crook J, Milner R, Schultz IZ, et al. Determinants of occupational disability following a low back injury: a critical review of the literature. J Occup Rehabil 2002;12:277-95.

4. Truchon M, Fillion L. Biopsychosocial determinants of chronic disability and low-back pain: a review. J Occup Rehabil 2000;10:117-42.

5. Loisel P, Durand $\mathrm{M}$, Berthelette $\mathrm{D}$, et al. Disability prevention: new paradigm for the management of occupational back pain. Disease Management and Health Outcomes 2001;9:351-60.

6. Shaw WS, Pransky G, Fitzgerald TE. Early prognosis for low back disability: intervention strategies for health care providers. Disabil Rehabil 2001;23:815-28.

7. Kuijer W, Groothoff JW, Brouwer S, et al. Prediction of sickness absence in patients with chronic low back pain: a systematic review. J Occup Rehabil 2006;16:439-67.

8. Hartvigsen J, Lings S, Leboeuf-Yde C, et al. Psychosocial factors at work in relation to low back pain and consequences of low back pain; a systematic, critical review of prospective cohort studies. Occup Environ Med 2004;61(1):e2.

9. Linton SJ. Occupational psychological factors increase the risk for back pain: a systematic review. J Occup Rehabil 2001;11:53-66.

10. Pengel LH, Herbert RD, Maher CG, et al. Acute low back pain: systematic review of its prognosis. BMJ 2003;327:323.

11. Pincus T, Burton AK, Vogel S, et al. A systematic review of psychological factors as predictors of chronicity/disability in prospective cohorts of low back pain. Spine 2002;27:E109-20.

12. Waddell G, Burton AK, Main CJ, eds. Screening to identify people at risk of longterm incapacity for work. London: Royal Society of Medicine Press, 2003.

13. Linton SJ, Gross D, Schultz IZ, et al. Prognosis and the identification of workers risking disability: research issues and directions for future research. J Occup Rehabil 2005; 15:459-74.

14. McIntosh G, Frank J, Hogg-Johnson S, et al. Low back pain prognosis: structured review of the literature. J Occup Rehabil 2000;10:101-15.

15. Steenstra IA, Verbeek JH, Heymans MW, et al. Prognostic factors for duration of sick leave in patients sick listed with acute low back pain: a systematic review of the literature. Occup Environ Med 2005;62:851-60.

16. Van Tulder MW, Assendelft WJ, Koes BW, et al. Method guidelines for systematic reviews in the Cochrane Collaboration Back Review Group for Spinal Disorders. Spine 1997;22:2323-30.

17. University of Rochester. Evidence-based filters for Ovid Medline (2002). Available from www.urmc.rochester.edu/hslt/miner/digital library/tip_sheets/OVID_eb_filters. pdf (accessed 19 May 2008).

18. Rutjes A, Reitsma J, Di Nisio M, et al. Design related bias and sources of variation in diagnostic accuracy studies. 12th Cochrane Colloquium: Bridging the Gaps; 2-6 October 2004, Ottawa, Ontario, Canada; 2004. Available from http://www.cochrane. org/colloquia/abstracts/ottawa/0-012.htm (accessed 18 May 2008).

19. Hayden JA, Cote P, Bombardier C. Evaluation of the quality of prognosis studies in systematic reviews. Ann Intern Med 2006;144:427-37.

20. Hoogendoorn WE, Bongers PM, De Vet HCW, et al. Psychosocial work characteristics and psychological strain in relation to low-back pain. Scand J Work Environ Health 2001;27:258-67.

21. Cats-Baril WL, Frymoyer JW. Identifying patients at risk of becoming disabled because of low-back pain. The Vermont Rehabilitation Engineering Center predictive model. Spine 1991;16:605-7.

22. Coste J, Delecoeuillerie G, Cohen de Lara A, et al. Clinical course and prognostic factors in acute low back pain: an inception cohort study in primary care practice. BMJ 1994;308:577-80.

23. Steenstra IA, Koopman FS, Knol DL, et al. Prognostic factors for duration of sick leave due to low-back pain in Dutch health care professionals. J Occup Rehabil 2005;15:591-605.
24. Lehmann TR, Spratt KF, Lehmann KK. Predicting long-term disability in low back injured workers presenting to a spine consultant. Spine 1993;18:1103-12.

25. Klenerman L, Slade PD, Stanley IM, et al. The prediction of chronicity in patients with an acute attack of low back pain in a general practice setting. Spine 1995;20:478-84.

26. Fritz JM, George SZ. Identifying psychosocial variables in patients with acute workrelated low back pain: the importance of fear-avoidance beliefs. Phys Ther 2002;82:973-83.

27. Fritz JM, George SZ, Delitto A. The role of fear-avoidance beliefs in acute low back pain: relationships with current and future disability and work status. Pain 2001;94:7-15.

28. Boersma K, Linton SJ. Screening to identify patients at risk: profiles of psychological risk factors for early intervention. Clin J Pain 2005;21:38-43.

29. Deyo RA, Diehl AK. Psychosocial predictors of disability in patients with low back pain. J Rheumatol 1988:15:1557-64.

30. Dionne CE, Bourbonnais $\mathrm{R}$, Fremont $\mathrm{P}$, et al. A clinical return-to-work rule for patients with back pain. CMAJ 2005;172:1559-67.

31. Gatchel RJ, Polatin PB, Mayer TG. The dominant role of psychosocial risk factors in the development of chronic low back pain disability. Spine 1995;20:2702-9.

32. Hagen EM, Svensen E, Ericksen HR. Predictors and modifiers of treatment effect influencing sick leave in subacute low back pain patients. Spine 2005;30:2717-23.

33. Haldorsen EMH, Indahl A, Ursin H. Patients with low back pain not returning to work: a 12-month follow-up study (including commentary by G Waddell). Spine 1998;23:1202-8

34. Hazard R, Haugh L, Reid S, et al. Early prediction of chronic disability after occupational low back injury. Spine 1996;21:945-51.

35. Infante-Rivard C, Lortie M. Prognostic factors for return to work after a first compensated episode of back pain. Occup Environ Med 1996;53:488-94.

36. Karjalainen K, Malmivaara A, Mutanen P, et al. Outcome determinants of subacute low back pain. Spine 2003;28:2634-40.

37. Lanier DC, Stockton P. Clinical predictors of outcome of acute episodes of low back pain. J Fam Pract 1988;27:483-7.

38. Nordin M, Skovron ML, Hiebert R, et al. Early predictors of delayed return to work in patients with low back pain. Journal of Musculoskeletal Pain 1997;5:5-27.

39. Ohlund C, Lindstrom I, Areskoug B, et al. Pain behavior in industrial subacute low back pain: I. Reliability: concurrent and predictive validity of pain behavior assessments. Pain 1994;58:201-9.

40. Schultz IZ, Crook J, Meloche GR, et al. Psychosocial factors predictive of occupational low back disability: towards development of a return-to-work model. Pain 2004;107:77-85.

41. Schultz IZ, Crook JM, Berkowitz J, et al. Biopsychosocial multivariate predictive model of occupational low back disability. Spine 2002:27:2720-5.

42. Shaw WS, Pransky G, Patterson W, et al. Early disability risk factors for low back pain assessed at outpatient occupational health clinics. Spine 2005;30:572-80.

43. Truchon M, Cote D. Predictive validity of the Chronic Pain Coping Inventory in subacute low back pain. Pain 2005;116:205-12.

44. Turner JA, Franklin G, Fulton-Kehoe D, et al. Worker recovery expectations and fearavoidance predict work disability in a population-based workers' compensation back pain sample. Spine 2006;31:682-9.

45. Van der Weide WE, Verbeek JHA, Salle HJA, et al. Prognostic factors for chronic disability from acute low-back pain in occupational health care. Scand J Work Environ Health 1999;25:50-6.

46. Schultz IZ, Crook J, Berkowitz J, et al. Predicting return to work after low back injury using the Psychosocial Risk for Occupational Disability instrument: a validation study. $J$ Occup Rehabil 2005;15:365-76.

47. Shaw WS, Huang YH. Concerns and expectations about returning to work with low back pain: identifying themes from focus groups and semi-structured interviews. Disabil Rehabil 2005;27:1269-81.

48. Mondloch MV, Cole DC, Frank JW. Does how you do depend on how you think you'll do? A systematic review of the evidence for a relation between patients' recovery expectations and health outcomes. CMAJ 2001;165:174-9.

49. Gross DP, Battie MC. Work-related recovery expectations and the prognosis of chronic low back pain within a workers' compensation setting. J Occup Environ Med 2005;47:428-33.

50. Venkataramanan V, Gignac MA, Mahomed NN, et al. Expectations of recovery from revision knee replacement. Arthritis Rheum 2006;55:314-21.

51. Zipori-Bechenstein P, Schechtman E, Socholitsky Z, et al. The relationship between pre-treatment attitudes and recovery: the cardiac catheterization example. Psychol Health Med 1999;4:377-85.

52. Heijbel B, Josephson M, Jensen I, et al. Return to work expectation predicts work in chronic musculoskeletal and behavioral health disorders: prospective study with clinical implications. J Occup Rehabil 2006;16:173-84.

53. Cole DC, Mondloch MV, Hogg-Johnson S. Listening to injured workers: how recovery expectations predict outcomes--a prospective study. CMAJ 2002;166:749-54.

54. Gross DP, Battie MC. Factors influencing results of functional capacity evaluations in workers' compensation claimants with low back pain. Phys Ther 2005;85:315-22.

55. Waddell G, Newton M, Henderson I, et al. A Fear-Avoidance Beliefs Questionnaire (FABO) and the role of fear-avoidance beliefs in chronic low back pain and disability. Pain 1993;52:157-68.

56. Waddell G. Pain and disability. In: The back pain revolution. 2nd ed. Edinburgh: Churchill Livingstone, 2004:27-44

57. Geisser ME, Robinson ME, Miller QL, et al. Psychosocial factors and functional capacity evaluation among persons with chronic pain. J Occup Rehabil 2003;13:259-76. 
58. Gatchel RJ. Psychosocial factors that can influence the self-assessment of function. J Occup Rehabil 2004;14:197-206.

59. Swinkels-Meewisse IE, Roelofs J, Oostendorp RA, et al. Acute low back pain: pain-related fear and pain catastrophizing influence physical performance and perceived disability. Pain 2006;120:36-43.

60. Swinkels-Meewisse IE, Roelofs J, Verbeek AL, et al. Fear-avoidance beliefs, disability, and participation in workers and non-workers with acute low back pain. Clin J Pain 2006;22:45-54.

61. Gheldof EL, Vinck J, Vlaeyen JW, et al. The differential role of pain, work characteristics and pain-related fear in explaining back pain and sick leave in occupational settings. Pain 2005;113:71-81.

62. George SZ, Fritz JM, McNeil DW. Fear-avoidance beliefs as measured by the fearavoidance beliefs questionnaire: change in fear-avoidance beliefs questionnaire is predictive of change in self-report of disability and pain intensity for patients with acute low back pain. Clin J Pain 2006:22:197-203.

63. Sieben JM, Vlaeyen JW, Tuerlinckx S, et al. Pain-related fear in acute low back pain: the first two weeks of a new episode. Eur J Pain 2002;6:229-37.

64. Vlaeyen JW, Linton SJ. Fear-avoidance and its consequences in chronic musculoskeletal pain: a state of the art. Pain 2000;85:317-32.

65. Sieben JM, Portegijs PJ, Vlaeyen JW, et al. Pain-related fear at the start of a new low back pain episode. Eur J Pain 2005:9:635-41.

66. Pincus T, Vogel S, Burton AK, et al. Fear avoidance and prognosis in back pain: a systematic review and synthesis of current evidence. Arthritis Rheum 2006;54:39994010.

67. Fishbain DA, Cutler R, Rosomoff HL, et al. Chronic pain-associated depression: antecedent or consequence of chronic pain? A review. Clin J Pain 1997:13:116-37.

68. Sullivan MJ, Adams $\mathrm{H}$, Thibault P, et al. Initial depression severity and the trajectory of recovery following cognitive-behavioral intervention for work disability. J Occup Rehabil 2006:16:63-74.

69. Paykel ES. Depression: major problem for public health. Epidemiol Psichiatr Soc 2006:15:4-10.

70. Dewa CS, Goering P, Lin E, et al. Depression-related short-term disability in an employed population. J Occup Environ Med 2002;44:628-33.

71. Goldberg RJ, Steury S. Depression in the workplace: costs and barriers to treatment. Psychiatr Serv 2001;52:1639-43.

72. D'Souza RM, Strazdins L, Broom DH, et al. Work demands, job insecurity and sickness absence from work. How productive is the new, flexible labour force? Aust N Z J Public Health 2006;30:205-12.

73. Sullivan T, Adler S. Work, stress, and disability. Int J Law Psychiatry 1999;22:417-24.

74. Jones DL, Tanigawa T, Weiss SM. Stress management and workplace disability in the US, Europe and Japan. J Occup Health 2003;45:1-7.

75. Gard G. Work motivating factors in rehabilitation: a brief review. Phys Ther Rev 2001;6:85-9.

76. Gard G, Sandberg AC. Motivating factors for return to work. Physiother Res Int 1998; 3:100-8.

77. Baril R, Clarke J, Friesen M, et al. Management of return-to-work programs for workers with musculoskeletal disorders: a qualitative study in three Canadian provinces. Soc Sci Med 2003;57:2101-14.

78. Young AE, Wasiak R, Roessler RT, et al. Return-to-work outcomes following work disability: stakeholder motivations, interests and concerns. J Occup Rehabil 2005; 15:543-56.

79. De Jonge J, Reuvers MM, Houtman IL, et al. Linear and nonlinear relations between psychosocial job characteristics, subjective outcomes, and sickness absence: baseline results from SMASH. Study on Musculoskeletal Disorders, Absenteeism, Stress, and Health. J Occup Health Psychol 2000;5:256-68.

80. Krause N, Dasinger LK, Deegan LJ, et al. Psychosocial job factors and return-to-work after compensated low back injury: a disability phase-specific analysis. Am J Ind Med 2001; 40:374-92.

81. Lippel K. Therapeutic and anti-therapeutic consequences of workers' compensation. Int J Law Psychiatry 1999:22:521-46.

82. Rogers R, Payne JW. Damages and rewards: assessment of malingered disorders in compensation cases. Behav Sci Law 2006:24:645-58.

83. Gatchel RJ, Adams L, Polatin PB, et al. Secondary loss and pain-associated disability: theoretical overview and treatment implications. J Occup Rehabil 2002;12:99-110.

84. Karjalainen K, Malmivaara A, van Tulder M, et al. Multidisciplinary biopsychosocial rehabilitation for subacute low back pain among working age adults. Cochrane Database Syst Rev 2003;(2):CD002193.

85. Ostelo RW, de Vet HC. Clinically important outcomes in low back pain. Best Pract Res Clin Rheumatol 2005:19:593-607.

86. Moher D, Cook DJ, Eastwood S, et al. Improving the quality of reports of metaanalyses of randomised controlled trials: the QUOROM statement. Quality of Reporting of Meta-analyses. Lancet 1999;354:1896-900.

\section{APPENDIX}

\section{Medline search strategy}

1 biopsychosocial.mp. (916)

2 psychosocial.mp. [ $\mathrm{mp}=$ title, original title, abstract, name of substance word, subject heading word] (17 625)

3 Psychological Techniques/or Feedback, Psychological/or Adaptation, Psychological/ or Stress, Psychological/or Psychological Tests/ (42 367)
4 Health Knowledge, Attitudes, Practice/ (22 262)

5 illness beliefs.mp. (68)

6 Attitude to Health/ (24 990)

7 Internal-External Control/ (4656)

8 health locus of control.mp. (277)

9 Personality/ (4269)

10 Personal Satisfaction/ (2389)

11 Psychological Tests/ (3909)

12 Anxiety/ (11 408)

13 Depression/ (16 941)

14 Avoidance Learning/ (3975)

15 fear avoidance.mp. (105)

16 FABO.mp. (16)

17 fear avoidance beliefs questionnaire.mp. (15)

18 fear avoidance beliefs.mp. (59)

19 yellow flags.mp. (11)

20 (psychosocial and risk factors).mp. [ $\mathrm{mp}=$ title, original title, abstract, name of substance word, subject heading word] (3161)

21 (SOPA and questionnaires).mp. [mp = title, original title, abstract, name of substance word, subject heading word] (1)

22 (orebro and questionnaires).mp. [ $\mathrm{mp}=$ title, original title, abstract, name of substance word, subject heading word] (28)

23 tampa scale of kinesiophobia.mp. (8)

24 (tampa and questionnaires).mp. [ $\mathrm{mp}=$ title, original title, abstract, name of substance word, subject heading word] (23)

25 kinesiophobia.mp. (37)

26 (pain vigilance and awareness questionnaire).mp. [mp $=$ title, original title, abstract, name of substance word, subject heading word] (2)

27 pain catastrophizing scale.mp. (26)

28 pain catastrophising scale.mp. (2)

29 pain anxiety symptoms scale.mp. (17)

30 pain coping questionnaire.mp. (5)

31 Coping strategies questionnaire.mp. (82)

32 (CSO and questionnaires).mp. [ $\mathrm{mp}=$ title, original title, abstract, name of substance word, subject heading word] (57)

33 ways of coping questionnaire.mp. (46)

34 (DRAM and questionnaires).mp. [mp = title, original title, abstract, name of substance word, subject heading word] (4)

35 zung depression.mp. (74)

36 (zung and questionnaires).mp. [ $\mathrm{mp}=$ title, original title, abstract, name of substance word, subject heading word] (91)

37 (depression and questionnaires).mp. [ $\mathrm{mp}=$ title, original title, abstract, name of substance word, subject heading word] (7336)

38 somatisation.mp. (136)

39 somatization.mp. (1090)

40 MSPQ.mp. (7)

41 pain catastrophising scale.mp. (2)

42 pain catastrophizing scale.mp. (26)

43 "distress and risk assessment method".mp. (8)

44 pain catastrophizing scale.mp. (26)

45 McGill pain questionnaire.mp. (423)

46 (MPQ and questionnaires).mp. [ $\mathrm{mp}=$ title, original title, abstract, name of substance word, subject heading word] (65)

47 "pain stages of change questionnaire".mp. (15)

48 (PSOCQ and questionnaires).mp. [ $\mathrm{mp}=$ title, original title, abstract, name of substance word, subject heading word] (9)

49 "pain vigilance and awareness questionnaire".mp. (2)

50 (nonorganic sign\$ or waddel\$ sign\$).mp. (31)

51 pain drawing.mp. (61)

52 symptom distress.mp. (322)

53 symptom distress scale.mp. (60)

$54 \mathrm{MMPI} /(881)$

55 guarding.mp. (361)

56 Self Efficacy/ (3225)

57 (self efficacy and questionnaires).mp. [mp = title, original title, abstract, name of substance word, subject heading word] (1770)

58 work APGAR.mp. (4)

59 or/1-58 (132 409)

60 back pain.mp. or exp back pain/ (11 447)

61 low back pain.mp. or exp low back pain/ (6960)

62 back injuries.mp. or exp back injuries/ (5159)

63 exp Spinal Stenosis/ (1133)

$64 \exp$ Sciatica/ (798)

65 exp Intervertebral Disk Displacement/ (3075)

66 exp Spondylolisthesis/or exp Spinal Diseases/or exp Spinal Injuries/or exp Spondylolysis/ (23 350)

67 or/60-66 (32 702)

68 exp Employment/ (15 597) 
69 work status.mp. (385)

70 return to work.mp. (1725)

71 exp Sick Leave/ (1286)

72 sick list\$.mp. (153)

73 exp absenteeism/ (1597)

74 time off work.mp. (205)

75 or/68-74 (19 438)

7659 and 67 and $75(189)$

77 exp Social Problems/or exp Social Perception/or exp Social Values/or exp Social Adjustment/or exp Social Change/or exp Social Conditions/or exp Social
Environment/or social.mp, or exp Social Class/or exp Psychology, Social/or exp Social Alienation/or exp Social Facilitation/or exp Hierarchy, Social/or exp Social Medicine/or exp Social Behavior/ (313 057)

7859 or 77 (384 247)

7978 and 67 and $75(290)$

80 limit 79 to "prognosis (sensitivity)" (129)

81 exp Job Satisfaction/or exp Workplace/or work environment.mp. (11 313)

8278 or 81 (389 923)

8382 and 67 and 75 (356)

84 limit 83 to "prognosis (sensitivity)" (143)

\section{BMJ Careers online re-launches}

BMJ Careers online has re-launched to give you an even better online experience. You'll still find our online services such as jobs, courses and careers advice, but now they're even easier to navigate and quicker to find.

New features include:

- Job alerts - you tell us how often you want to hear from us with either daily or weekly alerts

- Refined keyword searching making it easier to find exactly what you want

- Contextual display - when you search for articles or courses we'll automatically display job adverts relevant to your search

- Recruiter logos linked directly to their organisation homepage - find out more about the company before you apply

- RSS feeds now even easier to set up

Visit careers.bmj.com to find out more. 